\title{
Concurrent production of carotenoids and lipid by a filamentous microalga Trentepohlia arborum
}

\author{
Lin Chen ${ }^{\mathrm{a}, \mathrm{b}}$, Lanlan Zhang ${ }^{\mathrm{a}, \mathrm{c}}$, Tianzhong Liu ${ }^{\mathrm{a}, *}$ \\ a Key Laboratory of Biofuels, Qingdao Institute of Bioenergy and Bioprocess Technology, Chinese Academy of Sciences, Qingdao, Shandong 266101, People's Republic of China \\ ${ }^{\mathrm{b}}$ University of Chinese Academy of Sciences, Beijing 100049, People's Republic of China \\ ' College of Food Science and Engineering Ocean University of China, Qingdao 266003, People's Republic of China
}

\section{H I G H L I G H T S}

- T. arborum could simultaneously synthesize high amounts of carotenoids and lipid.

- Carotenoids (mainly $\beta$-carotene) accounted for $c a .5 \%$ in the microalgal lipid.

- First report of lipid and fatty acid accumulation characteristics in T. arborum.

\section{A R T I C L E I N F O}

\section{Article history:}

Received 8 March 2016

Received in revised form 5 May 2016

Accepted 6 May 2016

Available online 9 May 2016

\section{Keywords:}

$\beta$-Carotene

Fatty acid

Edible oil

Trentepohlia arborum

Microalga

\begin{abstract}
A B S T R A C T
During the study of Trentepohlia arborum it became clear that its cells are rich in lipids and carotenoids. Thus, lipid content, composition and fatty acids profiles in individual lipid classes, as well as pigment profiles, responding to different culture conditions, were further investigated. The results showed that the predominant carotenoids and lipid fraction in total lipid in this study was $\beta$-carotene and TAG, respectively. The lipid content increased significantly under high light while nitrogen-replete conditions induced the highest carotenoids content. However, only with a double stress of high light and nitrogen-deficiency it was possible to maximize the productivities of both carotenoids and lipids. Carotenoids (mainly $\beta$-carotene) accounted for $c a .5 \%$ of the microalgal lipid under the double stress. Data herein show the potential of $T$. arborum for the production of both lipids and carotenoids, and hence provide an appropriate way to produce different products from $T$. arborum.
\end{abstract}

(c) 2016 Elsevier Ltd. All rights reserved.

\section{Introduction}

Interest in microalgae for the production of biofuels, food and feed has increased in recent decades (Hu et al., 2008). Because of the relatively low price of fossil fuels, microalgae based biofuel production is currently uneconomical; it seems to be more realistic to produce biomass from microalgae as food and feed or as intermediate target (Klok et al., 2014; Urreta et al., 2014).

Many microalgae can biosynthesize and accumulate high levels of lipids in form of glycerolipids, such as triacylglycerols (TAG), phospholipids (PLs) and glycolipids (GLs) (Thompson, 1996). TAG represent the main fraction of edible oils (Gunstone, 2011), and PLs are generally used as aquaculture feed and accessories of functional food (Chen et al., 2008), because of this, the potential application of algal lipids are determined by the relative contents of individual lipid classes. Several microalgae species contain fatty

\footnotetext{
* Corresponding author.

E-mail address: liutz@qibebt.ac.cn (T. Liu).
}

acid profiles rich in special high-value polyunsaturated fatty acids (Chen et al., 2008; Chen, 2012), or general fatty acid similar to other more common vegetable oils (Thompson, 1996; Draaisma et al., 2013), hence different algal lipids would be used for bulk or specific applications. Thanks to their high content in carotenoid and tocopherol, recently, algal lipids have been used to improve the stability of vegetable oils, (Gouveia et al., 2007; Limon et al., 2015). Therefore, the applications of algal lipid are greatly expanded.

According to some reports, the lipids and pigments contents and compositions, as well as the fatty acids profiles in individual lipid class, changes significantly with different culture conditions (Hu et al., 2008; Chen, 2012). It should be noted that so far almost only unicellular microalgal species have been studied. Very few previous reports are available in the literature concerning multicellular microalgae, especially filamentous microalgae, even though these are proved to be superior to unicellular microalgae in resistant to grazers and cost for harvest (Wang et al., 2014; Chen et al., 2015). 
Trentepohlia arborum, a filamentous microalga, commonly grows aerially or subaerially in tropical, subtropical and temperate regions (Nash et al., 1987; Rindi et al., 2005; Allali et al., 2013). The morphological study of $T$. arborum and other species in this genus demonstrated the presence of large and copious lipid bodies (LBs) in the cytoplasm (Ho et al., 1983). This suggested that this filamentous microalga might have ability to generate high levels of lipid (Liu et al., 2012; Chen et al., 2015). Physiological aspects such as pigments compositions and the formation process of lipid bodies in Trentepohlia have been thoroughly studied (Ho et al., 1983; Chen et al., 2015), whereas the lipid content and composition and fatty acid files in T. arborum, or any other species of this genus, have not yet been examined. In addition, large amount of carotenoids was observed in T. arborum (Chen et al., 2015), mainly stored in the form of lipid bodies (Ho et al., 1983). That is to say, this microalga could accumulate carotenoids and lipids simultaneously.

In this study, both lipids and carotenoids productivities in filamentous microalgae $T$. arborum under various culture conditions were investigated. Additionally, the lipid composition and fatty acid profiles of individual lipid class responding to different culture conditions were also investigated. This study result is critical to promote the practical application of $T$. arborum in the functional and health food industry.

\section{Materials and methods}

\subsection{Strains and culture}

The filamentous algae T. arborum FACHB 1792 was obtained from the Freshwater Algae Culture Collection at the Institute of Hydrobiology, the Chinese Academy of Sciences, Wuhan, Hubei, China. The alga was maintained in solid BG11 medium containing $1 \%$ agar and cultured in liquid modified Bold's basal medium (BBM) under constant temperature of $25^{\circ} \mathrm{C}$ and light irradiance of $50 \mu \mathrm{mol} / \mathrm{m}^{2} / \mathrm{s}$.

The BBM was prepared following Abe's report (Abe et al., 2007). The medium contained $1.0 \mathrm{~g} \quad \mathrm{NH}_{4} \mathrm{Cl}, 175 \mathrm{mg} \quad \mathrm{KH}_{2} \mathrm{PO}_{4}, 75 \mathrm{mg}$ $\mathrm{K}_{2} \mathrm{HPO}_{4}, 25 \mathrm{mg} \mathrm{MgSO}_{4} \cdot 7 \mathrm{H}_{2} \mathrm{O}, 25 \mathrm{mg} \mathrm{NaCl}, 50 \mathrm{mg}$ EDTA, $30 \mathrm{mg}$ $\mathrm{KOH}, 5 \mathrm{mg} \mathrm{FeSO}{ }_{4} \cdot 7 \mathrm{H}_{2} \mathrm{O}$ and $11 \mathrm{mg} \mathrm{H}_{3} \mathrm{BO}_{3}$ in $1 \mathrm{~L}$ of deionized (DI) water ( $\mathrm{pH}$ adjusted prior to autoclaving to 8.0).

\subsection{Experiment and sample}

The alga strain was firstly grown in liquid BBM for 7 days and collected by gravity precipitation as follows; the cells were resuspended in fresh BBM and then cultured in a column bioreactor ( $3 \mathrm{~cm}$ diameter) with continuous bubbling by compressed air ( $2 \%$ $\mathrm{CO}_{2}, \mathrm{v} / \mathrm{v}$ ). Cultures of $T$. arborum were grown under different levels of nitrogen supplementation at a low light intensity of $35 \mu \mathrm{mol} / \mathrm{m}^{2} / \mathrm{s}$ (LL) and at a higher light intensity of $150 \mu \mathrm{mol} / \mathrm{m}^{2} / \mathrm{s}$ $(\mathrm{HL})$. The nitrogen supplementation levels were set as follows: 0 $(-\mathrm{N}), 9.4(+0.5 \mathrm{~N})$ and $18.7(+1.0 \mathrm{~N}) \mathrm{mmol} / \mathrm{L}$ ammonium chloride.

The algal cells were sampled every three days and then pelleted by filtration. The cells were lyophilized at $-80^{\circ} \mathrm{C}$ using a lyophilizer and were stored in a cool and dark place before analysis.

\subsection{Biomass determination}

Algae cells in 3-5 mL culture were collected using a pre-weighted nitrocellulose membrane filters $(0.25 \mu \mathrm{m}, \mathrm{NC}$ membrane) under vacuum, and then dried to constant weight at $105^{\circ} \mathrm{C}$ over $2 \mathrm{~h}$. The biomass dry weight was calculated as the difference between the weight of the membrane filter with and without cells on it.

\subsection{Morphology observation}

Images were taken with an Olympus SZX16 stereomicroscope and an Olympus BX 51 microscope; both were equipped with a DP 72 digital camera. The filaments length, number of branches and the size of colonies were obtained by measuring 50-100 filaments or colonies using the Olympus microscope and the DP2-BSW Ver. 2.2 software (Olympus, Japan).

\subsection{Analysis of pigment}

Pigments in cells were extracted with dimethyl sulfoxide (DMSO) after grinding under liquid nitrogen protection. Total amounts of chlorophyll and carotenoids were estimated using a Varian 50 Bio UV-Visible spectrophotometer (Varion Inc., US). Then the chlorophyll and total carotenoids content were calculated with the following equations (Wellburn, 1994):

Chlorophyll $a\left(\mathrm{C}_{a}\right)(\mu \mathrm{g} / \mathrm{mL})=12.19\left(\mathrm{OD}_{665}\right)-3.45\left(\mathrm{OD}_{649}\right)$
Chlorophyll $b\left(\mathrm{C}_{b}\right)(\mu \mathrm{g} / \mathrm{mL})=21.99\left(\mathrm{OD}_{649}\right)-5.32\left(\mathrm{OD}_{665}\right)$

Total carotenoids $\left(\mathrm{C}_{x+c}\right)(\mu \mathrm{g} / \mathrm{mL})$

$$
=\left(10000 D_{480}-2.14 C_{a}-70.16 C_{b}\right) / 220
$$

Car $/$ Chl ratio $=$ Total carotenoids $/$ Chlorophyll $a$

$$
+ \text { Chlorophyll } b \text { ) }
$$

The volumetric productivity of total carotenoids was calculated as follows:

Volumetric productivity $(\mathrm{mg} / \mathrm{L} / \mathrm{d})=\left(C_{t}-C_{o}\right) / t$

where the $C_{\mathrm{t}}$ and $C_{0}$ represented the volumetric content of carotenoids ( $\mathrm{mg}$ carotenoids in $1 \mathrm{~L}$ algal culture, $\mathrm{mg} / \mathrm{L}$ ) at day $t$ and day 0 respectively, and $t$ represented the time of cultivation (days).

Pigment profiles were analyzed using HPLC (Waters 1525, US) equipped with a 996 photodiode array detector (Waters 2998, US) following the methodology described by Yuan et al. (2002). Separation of carotenoids was achieved by the following gradient procedure: $0 \%$ of $\mathrm{B}$ for $8 \mathrm{~min}$; a linear gradient from $0 \%$ to $100 \%$ of B within $6 \mathrm{~min}$; $100 \%$ of $\mathrm{B}$ for $40 \mathrm{~min}$, at a flow rate of $1.0 \mathrm{~mL} / \mathrm{min}$. The mobile phase consisted of an eluent A (dichlor omethane:methanol:acetonitrile:water, 5.0:85.0:5.5:4.5, v/v) and

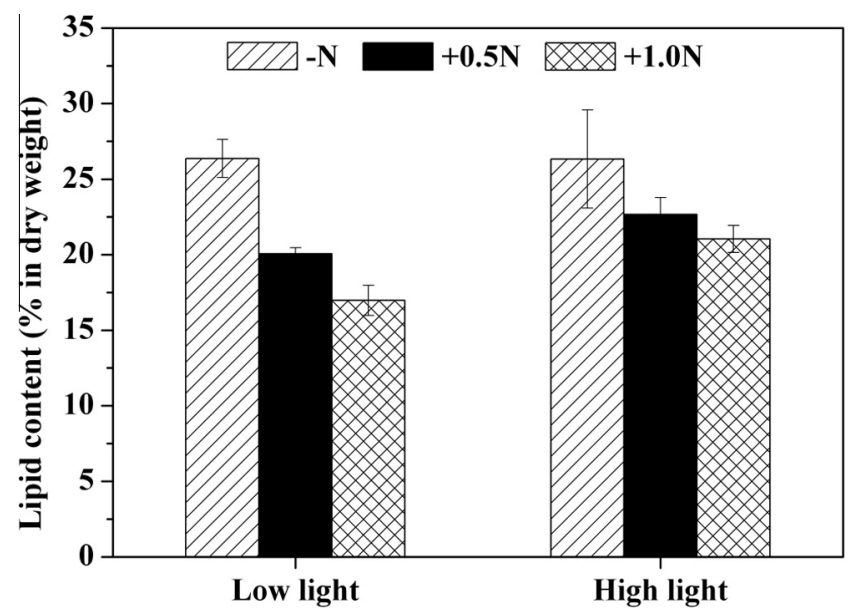

Fig. 1. The lipids contents of microalga Trentepohlia arborum grown in BBM containing $0(-\mathrm{N}), 9.4(+0.5 \mathrm{~N})$ and $18.7(+1.0 \mathrm{~N}) \mathrm{mmol} / \mathrm{L}$ ammonium chloride, and were illuminated under 35 (low light) or $150 \mu \mathrm{mol}$ photons $/ \mathrm{m}^{2} / \mathrm{s}$ (high light). Data are expressed as means \pm SD of three replicates. 

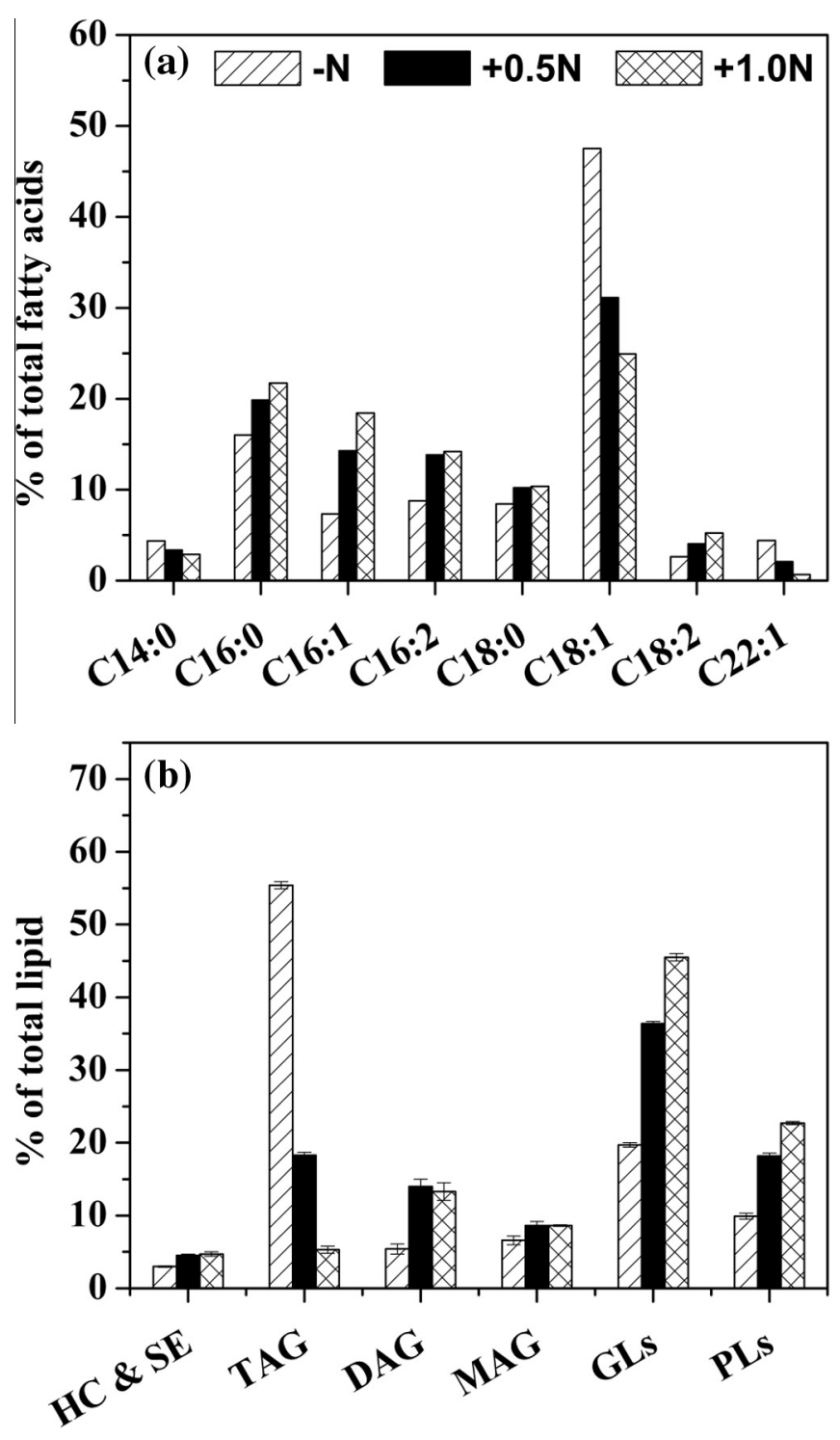

Fig. 2. The fatty acid profiles (a) and individual lipid class (b) in total lipids from microalga Trentepohlia arborum grown in BBM containing $0(-\mathrm{N}), 9.4(+0.5 \mathrm{~N})$ and $18.7(+1.0 \mathrm{~N}) \quad \mathrm{mmol} / \mathrm{L}$ ammonium chloride, and were illuminated under $35 \mu \mathrm{mol}$ photons $/ \mathrm{m}^{2} / \mathrm{s}$. Data are expressed as means \pm SD of three replicates. HC and SE, hydrocarbon and sterol ester; TAG, triacylglycerol; DAG, diacylglycerol; MAG, monoacylglycerol; GLs, glycolipids; PLs, phospholipids.

an eluent B (dichloromethane:methanol:acetonitrile:water, 25.0:28.0:42.5:4.5, v/v). The pigment extracts $(20 \mu \mathrm{L})$ were injected onto a Beckman Ultrasphere $\mathrm{C} 18$ reversed phase column $(5 \mu \mathrm{m} ; 250 * 4.6 \mathrm{~mm})$ at $30^{\circ} \mathrm{C}$. The absorption spectra of carotenoids were displayed between 250 and $700 \mathrm{~nm}$. The individual pigments in samples were identified by comparison of retentions times and spectrums with standards (Aladdin), and then the estimation of the quantity of the each carotenoid was carried out from the chromatogram peak areas.

\subsection{Analysis of lipid and fatty acids}

Total lipid was extracted with a solvent mixture of chloroform and methanol $(1: 2, \mathrm{v} / \mathrm{v})$, and then analyzed using gravimetric method (Bligh and Dyer, 1959). For lipid class analysis, lipid samples were dissolved in chloroform to a concentration of $5 \mathrm{mg} / \mathrm{mL}$. They were spotted onto thin-layer chromatography (TLC) plates coated with silica gel, and then developed in a solvent system of benzene:chloroform:acetic acid (150:60:2, v/v/v) for the first migration to $7 \mathrm{~cm}$, followed by a solution of benzene:hexane $(50: 50, v / v)$ for the second migration to $10 \mathrm{~cm}$. The lipid bands were stained by iodine vapor, and then each band was scraped off using a razor blade and to a tube containing $1 \mathrm{~mL}$ of chloroform and then lipid content of each band was determined gravimetrically. Alternatively, lipid class separation and analysis was carried out using a TLC coupled with a Flame Ionization Detector system (TLC-FID, MK-6, Iatron Laboratories, Inc., Japan) as described by Chen et al. (2012).

Total lipid and individual lipids were trans-methylated with $2 \%$ $\mathrm{H}_{2} \mathrm{SO}_{4}$ in methanol at $85^{\circ} \mathrm{C}$ for $2.5 \mathrm{~h}$. Then the fatty acids profiles were measured using gas chromatography (7890C, Agilent, US) equipped with a mass detector (5975A, Agilent, US). The fatty acid methyl esters were identified by comparison of retention times and mass spectrogram with standards (Sigma), and were quantified as follows:

$W=\frac{m_{\mathrm{S}} \times f_{\mathrm{i}} \times A_{\mathrm{i}}}{m \times A_{\mathrm{S}}} \times 100 \%$

where $W$ is the relative content of each fatty acid, presented as a percentage of total fatty acid; $m_{\mathrm{S}}$ is the mass of internal standard, $f_{\mathrm{i}}$ is the coefficient value of section $i, A_{\mathrm{i}}$ is the peak area of section $i, m$ is the weight of sample and $A_{\mathrm{S}}$ is the area of standard.

\subsection{Statistical analysis}

Statistical analysis was carried out using SPSS 11.0 software (SPSS Inc., Chicago, US). ANOVA was performed to evaluate significance of individual differences with a probability threshold of 0.05 , followed by a Post-Hoc Tukey test.

\section{Results and discussion}

3.1. Lipid accumulation and fatty acid profiles related to light intensity and nitrogen concentration

In order to examine the ability to produce lipid and valuable pigments, the microalga $T$. arborum was cultured in BBM medium

Table 1

Fatty acid profiling in individual lipid class of Trentepohlia arborum. ${ }^{\text {a }}$

\begin{tabular}{|c|c|c|c|c|c|c|c|c|c|c|c|c|c|c|}
\hline \multirow[t]{2}{*}{ Lipid class } & \multirow[t]{2}{*}{ Distribution (\% total lipid) } & \multicolumn{13}{|c|}{ Fatty acid composition (\% in total fatty acid) } \\
\hline & & $\mathrm{C} 14: 0$ & $\mathrm{C} 16: 0$ & $\mathrm{C} 16: 1$ & $\mathrm{C} 16: 2$ & $\Sigma C 16$ & C18:0 & C18:1 & $\mathrm{C} 18: 2$ & $\Sigma C 18$ & C22:1 & $\Sigma$ SFA & $\Sigma$ MUFA & $\Sigma$ PUFA \\
\hline $\mathrm{TAG}^{\mathrm{b}}$ & 55.4 & 5.8 & 17 & 7.5 & 5.9 & 30.4 & 4.3 & 51.1 & 2 & 57.4 & 6.3 & 27.1 & 64.9 & 7.9 \\
\hline DAG & 5.42 & 10.1 & 24.4 & 8.2 & 5.5 & 38.1 & 4.3 & 45.6 & 1.8 & 51.7 & 0.1 & 38.8 & 53.9 & 7.3 \\
\hline MAG & 6.55 & 2.3 & 56.5 & 3.1 & 3.0 & 62.6 & 32.1 & 2.8 & n.d. ${ }^{\mathrm{C}}$ & 34.9 & 0.2 & 90.9 & 6.1 & 3.0 \\
\hline GLs & 19.8 & 2.9 & 47.3 & 2.5 & 14.6 & 64.4 & 26.5 & 6.2 & n.d. & 32.7 & n.d. & 76.7 & 8.7 & 14.6 \\
\hline PLs & 9.8 & 13.2 & 63.7 & 4.1 & 1.5 & 69.3 & 11.4 & 5.5 & 0.6 & 17.5 & n.d. & 88.3 & 9.6 & 2.1 \\
\hline Total lipid & 100 & 4.4 & 18.1 & 7.3 & 7.7 & 33.1 & 8.4 & 47.5 & 1.6 & 57.5 & 4.4 & 30.9 & 59.2 & 9.3 \\
\hline
\end{tabular}

a The lipid was extracted from algae cultured in [LL-N].

b TAG, triacylglycerol; DAG, diacylglycerol; MAG, monoacylglycerol; GLs, glycolipids; PLs, phospholipids.

c n.d. not detected. 
for 14 days with different levels of nitrogen supplement under two light intensities. Many lipid bodies (LBs) were observed in T. arborum cells grown in nitrogen stress conditions (Supplementary Material Fig. 1), meaning that the strain contains high amounts of oil. The total lipid content for T. arborum with different levels of nitrogen supply under low and high light intensities was analyzed (Fig. 1). Regardless of the light intensity considered, the lower the nitrogen supplement, the higher the total lipid content. In particular, the lipid content was $c a .55 .3 \%$ higher in [LL-N] cultures than in [LL+1.0N] cultures. On the other hand, the alga accumulated $c a$. $13.0 \%$ and $23.9 \%$ more lipid under high light than low light in $+1.0 \mathrm{~N}$ and $+0.5 \mathrm{~N}$ cultures, whereas equal amount of lipid were observed under either two light intensities in $-\mathrm{N}$ cultures. Although both nitrogen deficiency and strong light could promote
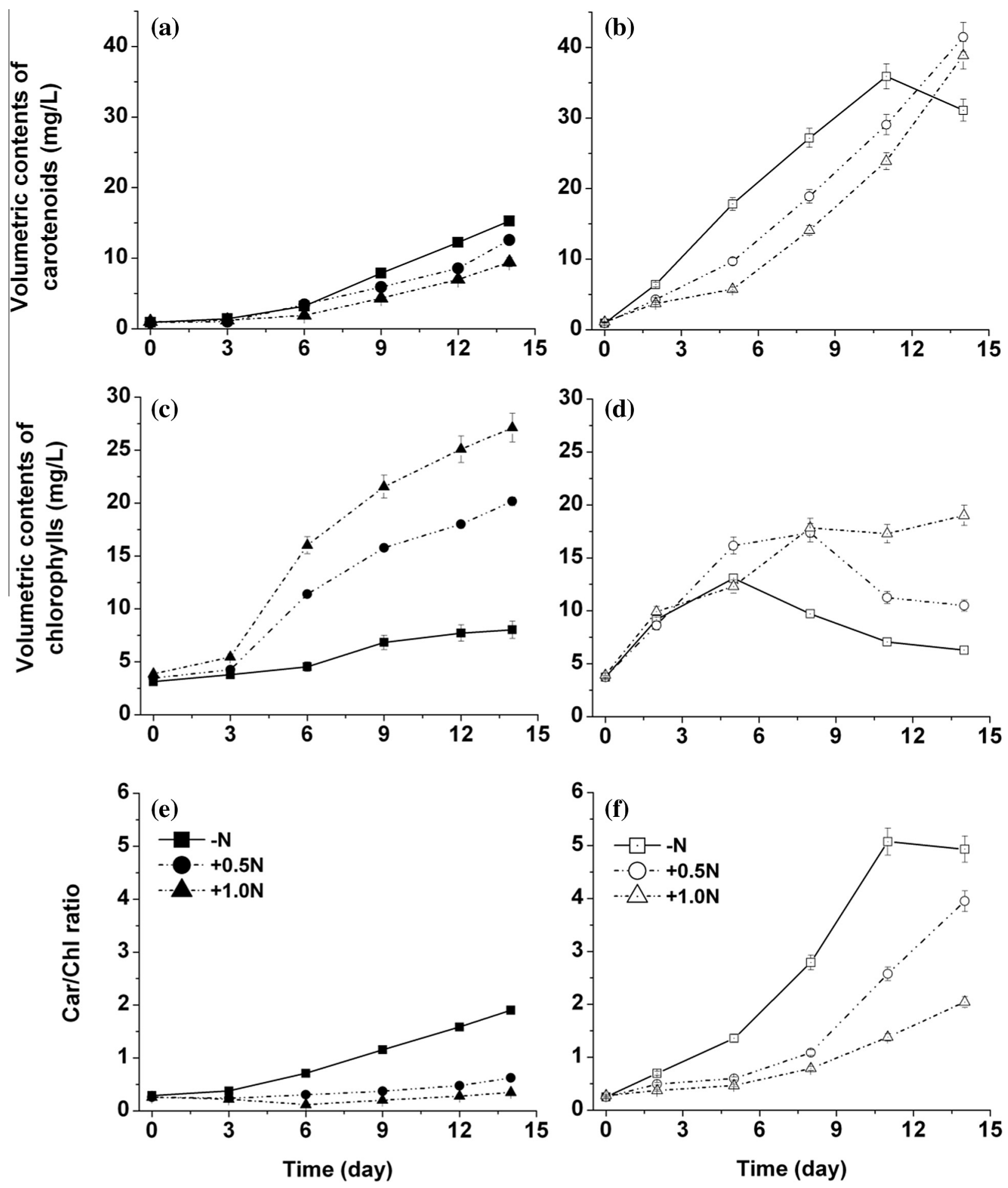

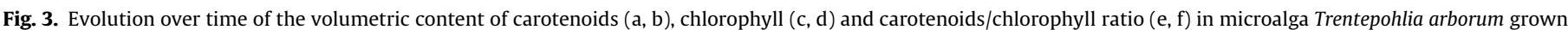

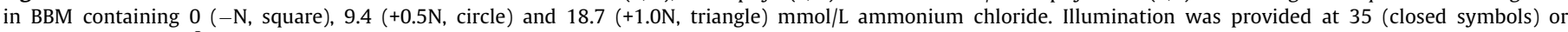
$150 \mu \mathrm{mol}$ photons $/ \mathrm{m}^{2} / \mathrm{s}$ (open symbols). 
lipid accumulation in T. arborum, there is no combined effect on lipid accumulation responding to double stress of high light and nitrogen deficiency. However, it seems clear that lipid accumulation in $T$. arborum was probably more sensitive to nitrogen starvation stress rather than strong light irradiance. Even though the lipid content in T. arborum is lower than that reported for the filamentous microalgae Tribonema minus (Wang et al., 2014), it is still comparable to filamentous algal Spirogyra singularis (Nabavi et al., 2013), and even much higher than Spirulina platensis (Zhang et al., 2015) and Limnothrix sp. (Economou et al., 2015).

Fig. 2a shows the fatty acid profiles of alga T. arborum in different nitrogen supply cultures at low light. It is apparent that fatty acids in all testing cultures were mainly composed of oleic acid (18:1), palmitic acid (16:0) and palmitoleic acid (16:1). As shown in Fig. 2a, the proportion of oleic acid (18:1), myristic acid (14:0) and erucic acid (22:1) decreased dramatically responding to nitrogen supply increase. In particular, the relative content of oleic acid in $+1.0 \mathrm{~N}$ culture was only half of that in $-\mathrm{N}$ cultures. On the contrary, the proportion of palmitic acid (16:0), palmitoleic acid (16:1), as well as other minor fatty acids, increased as the nitrogen supplement was incremented.

\subsection{Lipid composition related to culture conditions, and fatty acid distribution in individual lipid class}

Although polar lipids, especially GLs and PLs, could be used as functional food or feed (Schneider, 2001), TAG is more acceptable as cooking oil, due to its oxidative stability. Therefore, the information about lipid composition in total lipid is critical for determining the uses of lipid produced from this microalga. As shown in Fig. 2b, different levels of nitrogen supplement induced dramatic change on the relative contents of individual lipids. TAG was the predominant fraction ( $c a .55 .4 \%$ in total lipid) in lipid from $-\mathrm{N}$ cultures, but to be a secondary fraction in lipids from $+0.5 \mathrm{~N}$ and $+1.0 \mathrm{~N}$ cultures. The proportions of TAG among total lipid increased 3.5-fold and 10.5 -fold as the nitrogen was reduced to $0.5 \mathrm{~N}$ and $-\mathrm{N}$, respectively, while the proportions of GLs and PLs decreased in a smaller range (Fig. 2b). The overall increase in TAG under nitrogen deficiency $(-\mathrm{N})$ is most likely due to the up expression of de novo FAs biosynthesis, in addition to the conversion of polar lipids (PLs and GLs) into TAG triggered by nitrogen starvation, which has been reported in other green algae (Recht et al., 2014; Xia et al., 2015). A visible increase in relative contents of DAG, MAG and other lipid fractions following an increase of nitrogen supply was also observed.

The fatty acids profiling includes length of carbon chain and degree of insaturation for individual lipid classes of alga T. arborum. The characteristic of fatty acid profiles was different in each lipid class (Table 1). TAG, the largest fraction in total lipid, was mainly composed of oleic acid (18:1) and palmitic acid (16:0), minor amount of linoleic acid (18:2) and hexadecadienoic acid (16:2) were also present. Furthermore, TAG contained ca. 27.1\%, 64.9\% and $7.9 \%$ of saturated (SFA), monounsaturated (MUFA) and polyunsaturated fatty acids (PUFA), respectively. The smaller fraction of total lipid-PLs and GLs mainly contained short-chain fatty acids $(\leqslant \mathrm{C} 16)$ and palmitic acid (16:0) in particular (Table 1$)$. It should be noted that the fatty acid profile of TAG was similar to that of commercial olive oils (Limon et al., 2015), and therefore makes the TAG from alga T. arborum suitable to human consumption.

\subsection{Pigments content and carotenoids composition related to light intensity and nitrogen supply}

Fig. 3 shows how the volumetric content of chlorophyll and carotenoids changes over time in $T$. arborum cultures under different conditions. After 14 days of cultivation, the volumetric contents of carotenoids were ca. 9.4-folds, 14.0-folds and 16.8-folds the initial ones, for $+1 \mathrm{~N},+0.5 \mathrm{~N}$ and $-\mathrm{N}$ supplements respectively (Fig. 3a). In addition, the volumetric content of carotenoids in cells increased more rapidly at each nitrogen level with high light than if subjected to low light intensities (Fig. 3a and b). It is noteworthy that the volumetric content of carotenoids peaked (over $35.9 \mathrm{mg} / \mathrm{L}$ ) after 11 days under double stress of high light and nitrogen deficiency (Fig. 3b). The volumetric carotenoids productivity reached $3.18 \mathrm{mg} / \mathrm{L} /$ day, which is higher than what previously reported for the algal genus Trentepohlia in aquatic cultivation (Abe et al., 1999; Chen et al., 2015). However, at the last day of cultivation, the carotenoids content unexpectedly reduced slightly in $[\mathrm{HL}-\mathrm{N}]$ cultures, which suggested that a severe double stress might trigger the degradation of the accumulated. This phenomenon was also observed for Trentepohlia sp. in nature habitats, because of photo-bleaching induced by long exposure to high light intensities (Ortega-Morales et al., 2013). The nitrogen deficiency had a significant positive effect on carotenoids accumulation in T. arborum and other species in the same genus (Tan et al., 1993; Abe et al., 1998), which might depend on high expression levels of enzymes involved in de novo $\beta$-carotene synthesis, resembling that for Haematococcus pluvialis, under nitrogen deficiency (Recht et al., 2014).

The way chlorophyll was accumulated by $T$. arborum, particularly under high light intensity, differed significantly from how carotenoids were accumulated. As shown in Fig. 3d, the volumetric content of chlorophyll firstly increased and then began to decease linearly from day 5 and day 8 with $-\mathrm{N}$ and $+0.5 \mathrm{~N}$ supplements, respectively. The decline of chlorophyll content is a general response to nitrogen deficiency in green algae (Xia et al., 2015; Ikaran et al., 2015), since nitrogen is a major element in chlorophyll molecules and unavailable of this nutrient could prevent chlorophyll synthesis. Due to the combined effects of carotenoids accumulation and chlorophyll degradation, the Car/Chl ratio therefore increased much faster at high light than that at low light. Correspondingly, an obviously visible color variation from green to bright orange occurred in [LL-N] cultures, while still being green or yellow-green in $[\mathrm{LL}+0.5 \mathrm{~N}]$ and $[\mathrm{LL}+1.0 \mathrm{~N}]$ cultures (Supplementary Material Fig. 1). Moreover, the cells cultured at high light exhibited orange or reddish color with every testing nitrogen levels (Data not shown).

The pigment compositions of $T$. arborum cells under different cultivation conditions are shown in Table 2. The orange biomass contained $13.19 \mathrm{mg}$ of total carotenoids per gram of dry biomass, in which the major carotene profile was $\beta$-carotene (Table 2). Somewhat differently, the green biomass contained less total carotenoids ( $6.17 \mathrm{mg} / \mathrm{g}$ dry biomass), but was dominated in zeaxanthin (Table 2), which was considered as a new high value byproducts, such as coloring agents for human consumption, feed additives to enhance the pigmentation of fish, poultry and eggs, and also color enhancement in cosmetics and pharmaceutical products (Jin and Melis, 2003). Microalga T. arborum could generate an

Table 2

Pigments compositions in the green and orange cells of Trentepohlia arborum.

\begin{tabular}{lrr}
\hline \multirow{2}{*}{ Pigment } & $\mathrm{mg} / \mathrm{g}$ dry biomass \\
\cline { 2 - 3 } & Green cells $^{\mathrm{a}}$ & Orange cells $^{\mathrm{b}}$ \\
\hline Neoxanthin & $0.12 \pm 0.04$ & $0.06 \pm 0.02$ \\
Lutein & $0.10 \pm 0.01$ & $0.08 \pm 0.02$ \\
Zeaxanthin & $3.88 \pm 0.07$ & $0.56 \pm 0.04$ \\
Chlorophyll $a$ & $13.18 \pm 0.11$ & $1.23 \pm 0.05$ \\
Chlorophyll $b$ & $5.51 \pm 0.06$ & $1.49 \pm 0.03$ \\
$\beta, \beta$-Carotene & $1.72 \pm 0.01$ & $10.41 \pm 0.02$ \\
$\beta, \varepsilon$-Carotene & $0.35 \pm 0.01$ & $2.08 \pm 0.03$ \\
Total carotenoids & $6.17 \pm 0.03$ & $13.19 \pm 0.02$
\end{tabular}

a Algae grown in $[\mathrm{LL}+1.0 \mathrm{~N}]$ cultures for 14 days.

b Algae grown in $[\mathrm{HL}-\mathrm{N}]$ cultures for 14 days. 
Table 3

Carotenoids, lipid and biomass production of Trentepohlia arborum at different light intensity and ammonium concentrations for 14-days-cultivation. ${ }^{a}$

\begin{tabular}{|c|c|c|c|c|c|c|}
\hline \multicolumn{2}{|l|}{ Culture conditions } & \multirow{2}{*}{$\begin{array}{l}\text { Yield }(\mathrm{g} / \mathrm{L}) \\
\text { Biomass }\end{array}$} & \multicolumn{2}{|c|}{ Content (mg/g) } & \multicolumn{2}{|c|}{ Productivity (mg/L/day) } \\
\hline Ammonium (mmol/L) & Light $\left(\mu \mathrm{mol} / \mathrm{m}^{2} \mathrm{~s}\right)$ & & Carotenoids & Lipid & Carotenoids & Lipid \\
\hline 0 & 35 & $1.62 \pm 0.04$ & $9.44 \pm 0.03$ & $263.7 \pm 12.6$ & $1.09 \pm 0.00$ & $30.51 \pm 1.46$ \\
\hline 0 & 150 & $2.32 \pm 0.06$ & $13.40 \pm 0.11$ & $263.3 \pm 32.6$ & $2.22 \pm 0.02$ & $43.63 \pm 5.40$ \\
\hline 9.4 & 35 & $1.94 \pm 0.12$ & $8.12 \pm 0.10$ & $200.6 \pm 4.0$ & $1.13 \pm 0.01$ & $27.80 \pm 0.55$ \\
\hline 9.4 & 150 & $3.54 \pm 0.59$ & $11.71 \pm 0.07$ & $226.6 \pm 11.1$ & $2.96 \pm 0.02$ & $57.30 \pm 2.81$ \\
\hline 18.7 & 35 & $1.53 \pm 0.21$ & $6.17 \pm 0.09$ & $169.7 \pm 10.1$ & $0.67 \pm 0.01$ & $18.55 \pm 1.10$ \\
\hline 18.7 & 150 & $4.36 \pm 0.65$ & $8.92 \pm 0.13$ & $210.4 \pm 9.0$ & $2.78 \pm 0.04$ & $65.52 \pm 2.80$ \\
\hline
\end{tabular}

${ }^{\text {a }}$ Data are expressed as means $\pm \mathrm{SD}$ of three replicates.

amount of zeaxanthin ( $3.88 \mathrm{mg} / \mathrm{g}$ dry biomass) comparable to the highest value of zeaxanthin reported among algal species, Dunaliella salina zea1 (Jin et al., 2003).

\subsection{Co-production of lipid and carotenoid}

The contents and productivities of carotenoids and lipid under tested conditions were calculated and summarized in order to make a concise evaluation of the potential of $T$. arborum as a carotenoids and lipid source in Table 3. Both carotenoids and lipid contents were the highest under double stress of high light and nitrogen deficiency and reached to 13.40 and $263.3 \mathrm{mg}$ per gram of dry biomass, respectively. The lipid extracted in [HL-N] appeared bright yellow. Pigment analysis showed that this algal lipid contained high concentration of total carotenoids ( $\mathrm{ca} .5 \%$ in total lipid), which were mainly composed of $\beta$-carotene (Table 2). According to the previous reports, carotenoids from microalgae had excellent antioxidative ability (Abe et al., 2007; Gouveia et al., 2007; Limon et al., 2015), the lipid from T. arborum shall have an antioxidant potential in terms of special edible oil.

On the other hand, besides lipid and carotenoids accumulation, biomass production is also the important factor which should be considered. Table 3 showed that biomass yield can be notably enhanced by increment of nitrogen in the nutrient solution. For instance, increasing the nitrogen content from a condition of nitrogen deficiency $(-\mathrm{N})$ to a condition of nitrogen repletion $(+1 \mathrm{~N})$ induced a ca. 1.9-fold higher biomass yield under high light. Under this same condition, the contents of carotenoids and lipid slightly decreased, but their productivities significantly increased. Therefore, an appropriate way to produce different kind of products from T. arborum has been demonstrated.

\section{Conclusion}

The filamentous microalga $T$. arborum could simultaneously synthesize high amounts of carotenoids and lipid under double stress of high light and nitrogen deficiency. The predominant carotenoids and lipid fraction in total lipid from selected culture conditions was $\beta$-carotene and TAG, respectively. Fatty acid profiles were different in individual lipid class. These findings indicate good carotenoids and lipid production characteristics of T. arborum, making of it an interesting source of functional material for either the food or feed industry, in particular considering its potential as functional edible oil.

\section{Acknowledgements}

We would like to thank Prof. Guoxiang Liu and Dr. Huan Zhu from the Institute of Hydrobiology, CAS, for donating the strains. This work was supported by the Qingdao Institute of Bioenergy and Bioprocess Technology Director Innovation Foundation for Young Scientists (QIBEBT-DIFYS-201502). The authors thank
Dr. Hui Wang and Dr. Andrea Efrem Toninelli for their critical reading of the manuscript.

\section{Appendix A. Supplementary data}

Supplementary data associated with this article can be found, in the online version, at http://dx.doi.org/10.1016/j.biortech.2016.05. 017.

\section{References}

Abe, K., Mihara, H., Hirano, M., 1998. Characteristics of growth and carotenoid accumulation of the aerial microalga Trentepohlia aurea in liquid culture. J. Mar. Biotechnol. 6, 53-58.

Abe, K., Nishimura, N., Hirano, M., 1999. Simultaneous production of $\beta$-carotene vitamin E and vitamin C by the aerial microalga Trentepohlia aurea. J. Appl. Phycol. 11, 331-336.

Abe, K., Hattori, H., Hirano, M., 2007. Accumulation and antioxidant activity of secondary carotenoids in the aerial microalga Coelastrella striolata var. multistriata. Food Chem. 100, 656-661.

Allali, H.A., Rindi, F., Lopez-Bautista, J.M., 2013. Biodiversity of Trentepohliales (Ulvophyceae, Chlorophyta) in Gabon, Central Africa. Nova Hedwigia 96, 309324.

Bligh, E.G., Dyer, W.J., 1959. A rapid method of total lipid extraction and purification. Can. J. Biochem. Physiol. 37, 911-917.

Chen, Y.C., 2012. The biomass and total lipid content and composition of twelve species of marine diatoms cultured under various environments. Food Chem. 131, 211-219.

Chen, G.Q., Jiang, Y., Chen, F., 2008. Variation of lipid class composition in Nitzschic laevis as a response to growth temperature change. Food Chem. 109, 88-94.

Chen, L., Liu, T.Z., Zhang, W., Chen, X.L., Wang, J.F., 2012. Biodiesel production from algae oil high in free fatty acids by two-step catalytic conversion. Bioresour. Technol. 111, 208-214.

Chen, L., Zhang, L.L., Zhang, W., Liu, T.Z., 2015. Comparative analysis of growth and carotenoid accumulation of Trentepohlia arborum in aerial, subaerial, and aquatic cultivation. J. Appl. Phycol. 27, 1079-1087.

Draaisma, R.B., Wijffels, R.H., Slegers, P.M., Brentner, L.B., Roy, A., Barbosa, M.J., 2013. Food commodities from microalgae. Curr. Opin. Biotechnol. 24, 169-177.

Economou, C.N., Marinakis, N. Moustaka-Gouni, M., Kehayias, G., Aggelis, G. Vayenas, D.V., 2015. Lipid production by the filamentous cyanobacterium Limnothrix sp. growing in synthetic wastewater in suspended- and attachedgrowth photobioreactor systems. Ann. Microbiol. 65, 1941-1948.

Gouveia, L., Nobre, B.P., Marcelo, F.M., Mrejen, S., Cardoso, M.T., Palavra, A.F. Mendes, R.L., 2007. Functional food oil coloured by pigments extracted from microalgae with supercritical $\mathrm{CO}_{2}$. Food Chem. 101, 717-723.

Gunstone, F.D., 2011. Production and trade of vegetable oils. In: Gunstone, F.D. (Ed.) Vegetable Oils in Food Technology: Composition, Properties and Uses. WileyBlackwell, Oxford, pp. 1-24.

Ho, K.K., Tan, K.H., Wee, Y.C., 1983. Growth conditions of Trentepohlia odorata (Chlorophyta, Ulotrichales). Phycologia 22, 303-308.

Hu, Q., Sommerfeld, M., Jarvis, E., Ghirardi, M., Posewitz, M., Seibert, M., Darzins, A., 2008. Microalgal triacylglycerols as feedstocks for biofuel production: perspectives and advances. Plant J. 54, 621-639.

Ikaran, Z., Suarez-Alvarez, S., Urreta, I., Castanon, S., 2015. The effect of nitrogen limitation on the physiology and metabolism of Chlorella vulgaris var L3. Algal Res. 10, 134-144.

Jin, E., Melis, A., 2003. Microalgal biotechnology: carotenoid production by the green algae Dunaliella salina. Biotechnol. Bioprocess Eng. 8, 331-337.

Jin, E.S., Feth, B., Melis, A., 2003. A mutant of the green alga Dunaliella salina constitutively accumulates zeaxanthin under all growth conditions. Biotechnol. Bioeng. 81, 115-124.

Klok, A.J., Lamers, P.P., Martens, D.E., Draaisma, R.B., Wijffels, R.H., 2014. Edible oils from microalgae: Insights in TAG accumulation. Trends Biotechnol. 32, 521528.

Limon, P., Malheiro, R., Casal, S., Acien-Fernandez, F.G., Fernandez-Sevilla, J.M., Rodrigues, N., Cruz, R., Bermejo, R., Pereira, J.A., 2015. Improvement of stability 
and carotenoids fraction of virgin olive oils by addition of microalgae Scenedesmus almeriensis extracts. Food Chem. 175, 203-211.

Liu, G.X., Zhang, Q., Zhu, H., Hu, Z.Y., 2012. Massive Trentepohlia-bloom in a glacier valley of Mt. Gongga, China, and a new variety of Trentepohlia (Chlorophyta). PLoS One 7, e37725.

Nabavi, S.F., Nabavi, S.M., Ebrahimzadeh, M.A., Jafari, N., Yazdanpanah, S., 2013. Biological activities of freshwater algae, Spirogyra singularis Nordstedt. J. Aquat. Food Prod. Technol. 22, 58-65.

Nash, T.H., Kappen, L., Losch, R., Larson, D.W., Matthessears, U., 1987. Cold resistance of lichens with Trentepohlia-photobiont or Trebouxia-photobiont from the North-American West-coast. Flora 179, 241-251.

Ortega-Morales, B.O., Gaylarde, C., Anaya-Hernandez, A. Chan-Bacab, M.J. De Rosa-Garcia, S.C., Arano-Recio, D., Montero-M, J., 2013. Orientation affects Trentepohlia-dominated biofilms on Mayan monuments of the Rio Bec style. Int Biodeterior. Biodegrad. 84, 351-356.

Recht, L., Topfer, N., Batushansky, A., Sikron, N., Gibon, Y., Fait, A., Nikoloski, Z Boussiba, S., Zarka, A., 2014. Metabolite profiling and integrative modeling reveal metabolic constraints for carbon partitioning under nitrogen starvation in the green algae Haematococcus pluvialis. J. Biol. Chem. 289, 30387-30403.

Rindi, F., Sherwood, A.R., Guiry, M.D., 2005. Taxonomy and distribution of Trentepohlia and Printzina (Trentepohliales, Chlorophyta) in the Hawaiian Islands. Phycologia 44, 270-284.

Schneider, M., 2001. Phospholipids for functional food. Eur. J. Lipid Sci. Technol. 103, 98-101.
Tan, C.K., Lee, Y.K., Ho, K.K., 1993. Effect of light-intensity and ammonium-N on carotenogenesis of Trentepohlia odorata and Dunaliella bardawil. J. Appl. Phycol. 5, 547-549.

Thompson, G.A., 1996. Lipids and membrane function in green algae. Biochim. Biophys. Acta-Lipids Lipid Metab. 1302, 17-45.

Urreta, I., Ikaran, Z., Janices, I., Ibanez, E., Castro-Puyana, M., Castanon, S., SuarezAlvarez, S., 2014. Revalorization of Neochloris oleoabundans biomass as source of biodiesel by concurrent production of lipids and carotenoids. Algal Res. 5, 1622.

Wang, H., Ji, B., Wang, J.F., Guo, F.J., Zhou, W.J., Gao, L.L., Liu, T.Z., 2014. Growth and biochemical composition of filamentous microalgae Tribonema sp. as potential biofuel feedstock. Bioprocess. Biosyst. Eng. 37, 2607-2613.

Wellburn, A.R., 1994. The spectral determination of chlorophyll $a$ and chlorophyll $b$ as well as total carotenoids, using various solvents with spectrophotometers of different resolution. J. Plant Physiol. 144, 307-313.

Xia, L., Yang, H., He, Q., Hu, C., 2015. Physiological responses of freshwater oleaginous microalgae Desmodesmus sp. NMX451 under nitrogen deficiency and alkaline ph-induced lipid accumulation. J. Appl. Phycol. 27, 649-659.

Yuan, J.P., Chen, F., Liu, X., Li, X.Z., 2002. Carotenoid composition in the green microalga Chlorococcum. Food Chem. 76, 319-325.

Zhang, L.L., Chen, L., Wang, J.F., Chen, Y., Gao, X., Zhang, Z.H., Liu, T.Z., 2015. Attached cultivation for improving the biomass productivity of Spirulina platensis. Bioresour. Technol. 181, 136-142. 